\title{
Clinical, biochemical and hormone profile in hirsute vs nonhirsute patients with polycystic ovary syndrome
}

\author{
Iram Shabir, Sabhiya Majid, HardeepSingh, Shahnawaz Ahmad Mir
}

\begin{abstract}
Corresponding author: Dr Shahnawaz Ahmad Mir, Division of Internal Medicine and Endocrinology Government Medical College Srinagar, Jammu and Kashmir, India; Email mirdrshani@gmail.com
\end{abstract}

Distributed under Attribution-Non Commercial - Share Alike 4.0 International (CC BY-NC-SA 4.0)

\begin{abstract}
Background: Polycystic ovary syndrome (PCOS), a common endocrinopathy present with variety of phenotypes with broad spectrum of clinical symptoms. Hyperandrogenism characterized with the presence of hirsutism remains an important feature of PCOS. Aim: The present study was conducted to assess difference in the clinical, biochemical and hormone profile in hirsute and non-hirsute females with PCOS. Methods: Detailed physical and clinical history was taken in all subjects. Hormonal and biochemical assays were performed by ECLIA. Results: 105 normoglycemic cases were enrolled for this study. The mean age of patients was $22.19 \pm 4.4$ years and the mean age of menarche was $13.3 \pm 1.4$ years. Acne was present in more than $50 \%$ of our cases. $81 \%$ cases were hirsute and only $19 \%$ were nonhirsute. Mean fasting blood glucose and triglycerides were found to be statistically significant between the two groups. A positive trend of hirsutism was found to be associated with irregular cycles and family history of type-2 diabetes mellitus (T2DM). Conclusion: The mean blood glucose and triglycerides was elevated in hirsute PCOS, while as BMI, weight and waist circumference was slightly elevated in non-hirsute PCOS females.
\end{abstract}

Keywords: Polycystic ovary syndrome, hirsutism, irregular cycles, hyperandrogenism, testosterone.

Polycystic ovary syndrome (PCOS) is the most common endocrinopathy that affects females in the reproductive age ${ }^{1}$. These females present with variety of phenotypes with broad spectrum of clinical symptoms. The common symptoms include ovarian cysts, irregular menstrual cycles and hirsutism ${ }^{2}$. The etiology of this disorder is poorly understood, though insulin resistance, genetic and lifestyle factors have shown to be associated with its pathophysiology. Hyperinsulinemia contribute in a complicated manner to the hyperandrogenism by stimulating ovarian androgen secretion and inhibiting Sex hormone binding globulin (SHBG) secretion ${ }^{3,4}$.

Based on heterogeneous symptoms the diagnosis of
PCOS can be rather elusive. There are three sets of diagnostic criteria that define the diagnosis of PCOS: National Institutes of Health's (NIH) international conference on PCOS in 1990, the European Society of Human Reproduction and Embryology and the American Society for Reproductive Medicine (ESHRE/ASRM) in 2003 (referred to as the Rotterdam criteria), and the Androgen Excess Society \& PCOS Society (AE-PCOS) in $2006^{5}$. All the three criteria have specific diagnostic cutoff and due to the overlapping features of PCOS with other disorders, the prevalence of PCOS is difficult to determine with consistency. The NIH/NICHD and the Androgen Excess Society require signs or symptoms of hyperandrogenism

Received: $20^{\text {th }}$ November 2019. Accepted: $27^{\text {th }}$ January 2020.

Shabir I, Majid S, Singh H, Mir SA. Clinical, biochemical and hormone profile in hirsute vs nonhirsute patients with polycystic ovary syndrome. The New Indian Journal of OBGYN. 2020; 7(1): 36-40. 
such as hirsutism, orhyperandrogenemia, defined by elevated free testosterone, reduced SHBG, elevated free testosterone index, or elevated dehydroepiandrosterone sulphate. The ESHRE/ASRM (Rotterdam) criteria on the other hand allow the diagnosis of PCOS without the presence hyperandrogenism ${ }^{5,6}$.

Inspite of the differences in the criteria, hyperandrogenism still remains the important feature of PCOS. Clinically, hyperandrogenism is characterized by the presence of hirsutism that can be assessed by modified Ferrimann-Gallwey (FG) method ${ }^{7}$. The prevalence of hirsutism may vary in different races and ethnicities ${ }^{8}$. Kashmir being the northernmost state of India has conserved gene pool and ethinicity with high prevalence of hirsutism and PCOS 9, 10. Based on this, the present study was conducted to assess the clinical, biochemical and hormone profile in hirsute and nonhirsute PCOS females from this region.

\section{Methodology}

Patients diagnosed with the PCOS were the subjects for the present cross sectional study. The patients attended the department of Endocrinology for symptoms of hyperandrogenism such as hirsutism, severe acne, alopecia, infertility and menstrual disturbances in a period of one year (December 2016 to January 2018). The diagnosis was based on the criteria formulated by National Institute of Health / National Institute of Child Health and Human Development consensus conference ${ }^{5}$. The subjects who had any history of systemic sickness such as known diabetes or abnormal glucose tolerance, heart conditions, current or pregnancy, lactation, history of drug intake such as steroids, androgens, oral contraceptives, anti-epileptics or drugs known to interfere in glucose or lipid metabolism were excluded from the study.

Detailed physical and clinical history was taken in all subjects. Oligomenorrhea was defined as an inter menstrual interval of $>35$ days or a total of $<8$ menses per year. Amenorrhea was defined as absence of menstruation during last 6 or more months. Anthropometric assessment like measurement of height $(\mathrm{Ht})$, weight, body mass index (BMI), waist/hip circumference, blood pressure and detailed systemic examination was done. BMI was calculated by the formula: Body Wt. $(\mathrm{kg}) / \mathrm{Ht}\left(\mathrm{m}^{2}\right)$. Hirsutism was assessed using modified FG score by counting nine specified body areas by a single observer with a good reproducibility ${ }^{7}$. A score of $>9$ out of a total of 36 was taken as significant ${ }^{11}$. Acne vulgaris was assessed in all subjects and, moderate to severe acne was taken as a clinical feature of hyperandrogenemia. Fasting blood glucose was done after 10-12 hours of overnight fast. The samples were collected in Ethylene diamine tetra acetic acid (EDTA) coated vials under cold conditions. Blood samples were collected from all the subjects after an overnight fast (10 to12 hours) for biochemical and hormone estimation. The samples for leutinizing hormone (LH), follicle stimulating hormone (FSH) and testosterone (T) were collected on days 3rd -7th (early follicular phase) of spontaneous or medroxyprogesterone induced (in amenorrhea patients) menstrual cycle. All the patients were subjected to transabdominal ultrasonography (USG). The USG was done to record typical features of PCOS (multiple small peripheral cysts, increased ovarian volume and thecal hyperechogenecity) and to rule out any adrenal or ovarian mass lesion.

Hormonal and biochemical assays were performed by electro-chemilumniscence (ECLIA) using commercial kits in duplicate and according to supplier protocol (Abbott Germany; Siemens USA). The assays were performed on auto-analysers Abbott i1000SRXP and Siemens Advia centaur XP. Serum insulin was measured by Enzyme linked immuno sorbent assay (ELISA) using kit supplied by Calbiotech, India. Intra and inter-assay variations were within the limits as specified by manufacturer.This study was approved and conducted according to the guidelines of ethical committee of Government Medical College Srinagar.

Statistical analysis was done using SPSS version1.5 software (Lead Technologies, Lead, US). The continuous data were expressed as mean \pm SD. Student's unpaired t-test was used for comparison. Partial correlation was performed for adjusting for confounding variables like BMI and fasting blood glucose. Tests were considered significant at $\mathrm{P} \leq 0.05$.

\section{Results}

One hundred and five normoglycemic cases were enrolled for this study. The mean age of patients was $22.19 \pm$ 4.4 years (14 to 38 years) and the mean age of menarche was at $13.3 \pm 1.4$ years ( 9 to 17 years). Irregular cycles were present in 85/105 (81\%) patients. Acne was present in 59 out of 105 cases $(56 \%)$. Thirty three cases $(31 \%)$ had grade I acne, 18 cases (17\%) had grade II acne and 8 cases $(7.5 \%)$ had grade III acne. FG score $\geq 9$ was present in $85 / 105$ (81\%) patients. Sixty three cases $(60 \%)$ had family history of type- 2 diabetes mellitus.

We divided our cases into two groups: Group A in which FG score $\geq 9$ and Group B in which FG score $<9$. In group 
Table 1: Clinical profile of the hirsute and non-hirsute females with PCOS.

\begin{tabular}{llll}
\hline Parameters & $\begin{array}{l}\text { Group A } \\
\text { mean } \pm \text { SD }(\mathbf{N}=\mathbf{8 5})\end{array}$ & $\begin{array}{l}\text { Group B } \\
\text { mean } \pm \text { SD (N=20) }\end{array}$ & P value \\
\hline Age (years) & $22.7 \pm 4.3$ & $20.6 \pm 4.12$ & 0.04 \\
Age of menarche (years) & $13.2 \pm 1.4$ & $13.3 \pm 1.3$ & 0.76 \\
Weight (kg) & $60.8 \pm 10.2$ & $64.6 \pm 12.8$ & 0.53 \\
Height (cm) & $153.8 \pm 7.3$ & $152.8 \pm 2.3$ & 0.15 \\
Waist (cm) & $87.5 \pm 10$ & $90.5 \pm 12.9$ & 0.24 \\
Hip (cm) & $94.7 \pm 12.7$ & $93.9 \pm 10.89$ & 0.79 \\
BMI & $25.8 \pm 5.2$ & $27.62 \pm 5.05$ & 0.15 \\
FG score & $14.8 \pm 3.9$ & $7.14 \pm 1.4$ & $<0.001$ \\
\hline
\end{tabular}

Note: BMI - body mass index, FG score - Ferriman-Gallwey Score

A, 53/85 (62\%) cases had family history of diabetes cycles. In group B, 10/20 (48\%) cases had family history of mellitus type 2 (T2DM) and 69/85 (81\%) had irregular T2DM and only 16/20(76\%) had irregular cycles. In group

Table 2: Biochemical profile of the hirsute and non-hirsute females with PCOS.

\begin{tabular}{llll}
\hline Biochemical parameters & $\begin{array}{l}\text { Group A } \\
\text { mean } \pm \text { SD }\end{array}$ & $\begin{array}{l}\text { Group B } \\
\text { mean } \pm \text { SD }(\mathbf{N}=\mathbf{2 0})\end{array}$ & P value \\
\hline Fasting blood glucose (mg/dl) & $91 \pm 9.6$ & $85.6 \pm 9.2$ & 0.02 \\
Cholesterol (mg/dl) & $184.9 \pm 38.3$ & $176.6 \pm 31$ & 0.35 \\
Triglycerides (mg/dl) & $167.4 \pm 54.3$ & $124.9 \pm 41.6$ & $<0.001$ \\
HDL-c (mg/dl) & $46 \pm 7.7$ & $45.6 \pm 7.7$ & 0.83 \\
LDL-c (mg/dl) & $107.4 \pm 21.8$ & $102.2 \pm 27.2$ & 0.35 \\
Urea(mg/dl) & $18.8 \pm 4.6$ & $18 \pm 3.8$ & 0.46 \\
Creatinine(mg/dl) & $0.73 \pm 0.13$ & $0.71 \pm 0.13$ & 0.52 \\
Total Protein (g/dl) & $10.2 \pm 13$ & $7.7 \pm 0.58$ & 0.38 \\
Total Bilirubin (mg/dl) & $0.66 \pm 0.27$ & $0.56 \pm 0.25$ & 0.12 \\
Albumin (g/dl) & $4.2 \pm 0.30$ & $4.3 \pm 0.31$ & 0.17 \\
AST (U/l) & $31 \pm 9.8$ & $29.5 \pm 8.3$ & 0.50 \\
ALT (U/l) & $30.16 \pm 12.9$ & $31.6 \pm 13.9$ & 0.65 \\
ALP (U/l) & $94.8 \pm 21.4$ & $99.2 \pm 25.15$ & 0.41 \\
\hline
\end{tabular}

Note: HDL-c - High density lipoprotein, LDL-c - low density lipoprotein, AST - Aspartate transaminase, ALT - Alanine transaminase, ALP - Alkaline Phosphatase

Table 3: Hormone profile of the hirsute and non-hirsute females with PCOS.

\begin{tabular}{llll}
\hline Hormonal parameters & $\begin{array}{l}\text { Group A } \\
\text { mean } \pm \text { SD }(\mathbf{N}=\mathbf{8 5})\end{array}$ & $\begin{array}{l}\text { Group B } \\
\text { mean SD }(\mathbf{N}=\mathbf{2 0})\end{array}$ & P value \\
\hline $\mathrm{LH}(\mu \mathrm{IU} / \mathrm{ml})$ & $4.17 \pm 1.9$ & $4.9 \pm 2.7$ & 0.15 \\
FSH $(\mu \mathrm{IU} / \mathrm{ml})$ & $5.3 \pm 1.5$ & $5.6 \pm 1.6$ & 0.41 \\
Testosterone $(\mathrm{ng} / \mathrm{ml})$ & $0.53 \pm 0.36$ & $0.52 \pm 0.27$ & 0.90 \\
Prolactin $(\mathrm{ng} / \mathrm{dl})$ & $14.4 \pm 4.6$ & $15.1 \pm 4.17$ & 0.52 \\
T3 $(\mu \mathrm{I} / \mathrm{ml})$ & $1.27 \pm 0.25$ & $1.3 \pm 0.28$ & 0.63 \\
T4 $(\mu \mathrm{I} / \mathrm{ml})$ & $6.7 \pm 0.89$ & $6.6 \pm 1.03$ & 0.65 \\
TSH $(\mu \mathrm{I} / \mathrm{ml})$ & $2.7 \pm 1.06$ & $2.7 \pm 1.05$ & 1.0 \\
Fasting Insulin $(\mu \mathrm{IU} / \mathrm{ml})$ & $6.5 \pm 7.7$ & $6 \pm 4.5$ & 0.77 \\
\hline Note: $\mathrm{LH}$ - Leutinizing hormone, FSH - Follicle stimulating hormone, TSH - Thyroid stimulating hormone \\
\hline
\end{tabular}


A, grade III acne was present in 8 cases $(9.4 \%)$ while in group B grade III acne was not found in any patient. The details of their clinical, biochemical and hormonal parameters are given in table 1, 2 and 3.

\section{Discussion}

The main source of androgens in females is ovaries and excess androgens have been reported in many females with PCOS. It has been reported that $80 \%$ of PCOS females have increased androgens, that may be due to up-regulation of adrenocortical axis ${ }^{12,13}$. Hyperandrogenism described as the presence of hirsutism, acne and/or alopecia can be diagnosed clinically or by the presence of androgens in blood ${ }^{14}$.

In our study $59 \%$ cases had acne that revealed an important sign of androgen excess disorder. Similar study conducted by Uysal et al showed that three quarters of patients presented with acne ${ }^{15}$. Seventy four percent of women with acne were found to have PCOS by the study conducted by Eden et al ${ }^{16}$. Another study by Franik et al showed that moderate to severe acne was present in about $18.2 \%$ (20 cases/110 cases) ${ }^{17}$, however the prevalence of acne was present in more than $50 \%$ of our cases.

The common cause of hirsutism in PCOS females has been generally attributed to the overproduction of androgens by the ovaries ${ }^{18}$. In our study, we found that $85 / 105(81 \%)$ cases were hirsute and only 20/105 (19\%) were non-hirsute, a large study conducted by Aziz et al. found 78.4\% PCOS cases presented with hirsutism ${ }^{19}$. In another study however, Asian females were found to be less hirsute when compared to the Caucasian groups ${ }^{8}$. In our study, sixty three cases (60\%) had family history of type 2 diabetes mellitus and irregular cycles were present in $85 / 105(81 \%)$ patients. This genetic factor may somehow release more insulin that will in-turn stimulate the ovaries to produce more androgens leading to hirsutism, acne or irregular cycles ${ }^{20}$. Though the difference was not statistically significant between group A and group B of our cases, but a positive trend of hirsutism was found to be associated with irregular cycles and family history of T2DM.

The subjects in our study were normoglycemic, mean fasting blood glucose and triglycerides were found to be statistically significant between the two groups. The mean fasting blood glucose was elevated $(91 \pm 9.6 \mathrm{mg} / \mathrm{dl})$ in hirsute womenwhen compared to the non-hirsute $(85.6 \pm 9.2 \mathrm{mg} / \mathrm{dl})$. Also the mean triglycerides were found to be increased in hirsute $(167.4 \pm 54.3 \mathrm{mg} / \mathrm{dl})$ when compared to the nonhirsute cases $(124.9 \pm 41.6 \mathrm{mg} / \mathrm{dl})$. The association of glucose metabolism with hirsutism is a well-defined entity.
Hyperinsulinemia elevates blood glucose and hyperlipidemia modifies the activity of cytochrome P450 in women with PCOS that lead to increased secretion or activity of androgens in these women ${ }^{21}$. Few studies have shown that insulin and blood glucose play a vital role in the stimulation of hair follicle growth and further increases the activity of either skin $5 \alpha$ - reductase activity or alters skin androgen receptor $^{22}$.

It is worth mentioning that our non-hirsute group was slightly more obese as compared to the hirsute women. Though the difference between the two groups was statistically non-significant, but an increased trend was observed. Similar results were earlier reported by Shabir I et al, where they found a trend for less acne and hirsutism with increase in $\mathrm{BMI}{ }^{13}$.

\section{Conclusion}

We conclude that fasting blood glucose and triglycerides were elevated in hirsute PCOS, while as BMI, weight and waist circumference was slightly elevated in non-hirsute PCOS females.

\section{Conflict of interest: None. Disclaimer: Nil.}

\section{References}

1. Azziz R, Woods KS, Reyna R, Key TJ, Knochenhauer ES, Yildiz BO. The prevalence and features of the polycystic ovary syndrome in an unselected population. J Clin Endocrinol Metab. 2004; 89: 2745-9.

2. March WA, Moore VM, Willson KJ. The prevalence of polycystic ovary syndrome in a community sample assessed under contrasting diagnostic criteria. Hum. Reprod. 2010; 25: 544-51.

3. Sirmans SM, Pate KA. Epidemiology, diagnosis, and management of polycystic ovary syndrome. ClinEpidemiol. 2013; 6: 1-13.

4. Rojas J, Chavez M, Olivar L, Rojas M, Morillo J, Mejías J,et al. Polycystic ovary syndrome, insulin resistance, and obesity: Navigating the pathophysiologic labyrinth. Int J Reprod Med. 2014; 2014:719050

5. Lujan ME, Chizen DR, Pierson RA. Diagnostic criteria for polycystic ovary syndrome: Pitfalls and controversies. J Obstet Gynaecol Can. 2008; 30: 671-9.

6. Nadaraja RND, Sthaneshwar P, Razali N. Establishing the cut off values of androgen markers in the assessment of polycystic ovarian syndrome. Malaysian J Pathol. $2018 ; 40(1): 33-9$ 
The New Indian Journal of OBGYN. 2020 (July-December); 7(1)

7. Wild RA, Vesely S, Beebe L, Whitsett T, Owen W. Ferriman Gallwey self-scoring I: Performance assessment in women with polycystic ovary syndrome. $\mathrm{J}$ Clin Endocrinol Metab. 2005; 90: 4112-4.

8. Wolf WM, Wattick RA, Kinkade ON, Olfert MD. Geographical Prevalence of Polycystic Ovary Syndrome as Determined by Region and Race/Ethnicity. Int $\mathrm{J}$ Environ Res Public Health. 2018; 15(11): 2589.

9. Ganie MA, Marwaha RK, Dhingra A, Nisar S, Mani K, Masoodi S, at al. Observation of phenotypic variation among Indian women with polycystic ovary syndrome (PCOS) from Delhi and Srinagar. Gynecol Endocrinol. 2016; 32(7): 566-70.

10. Zargar AH, Wani AI, Masoodi SR, Laway BA, Bashir MI, Salahuddin M. Epidemiologic and etiologic aspects of hirsutism in Kashmiri women in the Indian subcontinent. Fertil Steril. 2002; 77(4): 674-8.

11. Adityan B, Kumari R, Thappa DM. Scoring systems in acne vulgaris. Indian J Dermatol Venereol Leprol. 2009; 75: 323-6.

12. Walker M, Berrish TS, James AR, Alberti KG. Effect of hyperinsulinaemia on the function of the pituitaryadrenal axis in healthy man. Clin Endocrinol (Oxf). 1994; 40: 493-7.

13. Shabir I, Ganie MA, Praveen EP, Khurana ML, John J, Gupta N, et al. Morning plasma cortisol is low among obese women with polycystic ovary syndrome. Gynecol Endocrinol. 2013; 29(12): 1045-7.

14. Pasquali R, Zanotti L, Fanelli F, Mezzullo M, Fazzini A, Morselli Labate AM, et al. Defining hyperandrogenism in women with polycystic ovary syndrome: A challenging perspective. J Clin Endocrinol Metab. 2016; 101: 2013-22.

15. Uysal G, Sahin Y, Unluhizarci K, Ferahbas A, Uludag $\mathrm{SZ}$, Aygen E, et al. Is acne a sign of androgen excess disorder or not? Eur J Obstet Gynecol Reprod Biol. 2017; 211: 21-5.

16. Eden JA. The polycystic ovary syndrome presenting as resistant acne successfully treated with cyproterone acetate. Med J Aust. 1991; 155: 677-80.

17. Franik G, Bizoń A, Włoch S, Kowalczyk K, BiernackaBartnik A, Madej P. Hormonal and metabolic aspects of acne vulgaris in women with polycystic ovary syndrome. Eur Rev Med Pharmacol Sci. 2018; 22(14):4411-8.

18. Sagvekar P, Dadachanji R, Patil K, Mukherjee S. Pathomechanisms of polycystic ovary syndrome: Multidimensional approaches. Front Biosci (Elite Ed). 2018; 10: 384-422.

19. Aziz R, Sanchez LA, Knochenhauer ES, Moran C, Lazenby J, Stephens KC, et al. Androgen excess in women: experience with over 1000 consecutive patients. J Clin Endoc Metab. 2004; 89: 453-62.

20. Rosenfield RL. Polycystic ovary syndrome and insulinresistant hyperinsulinemia. J Am Acad Dermatol. 2001; 45: 95-104.

21. Cebeci F, Onsun N, Mert M. Insulin resistance in women with hirsutism. Arch Med Sci. 2012; 8(2): 342-6.

22. Aziz R, Carmina E, Sawaya ME. Idiopathic hirsutism. Endoc Rev. 2000; 21: 347-62.
Iram Shabir ${ }^{1}$, Sabhiya Majid ${ }^{2}$, HardeepSingh ${ }^{3}$, Shahnawaz Ahmad Mir ${ }^{4}$
${ }^{1}$ Lecturer, Department of Biochemistry; ${ }^{2}$ Head Department of Biochemistry; ${ }^{3}$ Division of Internal Medicine and Endocrinology; ${ }^{4}$ Division of Internal Medicine and Endocrinology Government Medical College Srinagar, Jammu and Kashmir, India. 